\title{
Tropical Cyclones Affecting Tokyo and Changing Storm Surge Hazard since 1980
}

Md. Rezuanul Islam ${ }^{1,{ }^{*}}$, Masaki Satoh ${ }^{2}$, and Hiroshi Takagi ${ }^{1}$

1 Department of Transdisciplinary Science and Engineering, School of Environment and Society, Tokyo Institute of Technology, Tokyo 152-8550, Japan

2 Atmosphere and Ocean Research Institute, The University of Tokyo, Tokyo, Japan *Corresponding author. Email: fahiemislam@gmail.com

*This manuscript is a non-peer reviewed preprint submitted to EarthArXiv and currently under consideration at Journal of the Meteorological Society of Japan. Subsequent versions of this manuscript may have slightly different content. If accepted, the final version will be available via the "Peer-reviewed Publication DOI" link on the Earth ArXiv webpage. 


\begin{abstract}
This study investigated tidal records and landfall tropical cyclone (TC) best tracks in Japan from 1980 to 2019 to determine changes in storm surge heights in coastal regions of eastern Japan, including Tokyo. The results indicate that annual mean storm surge heights have increased in the last 20 years (2000-2019) compared to those in 19801999, and that these changes are noteworthy, particularly in Tokyo Bay. The storm surge hazard potential index (SSHPI), proposed by Islam et al. (2021), is positively correlated with surge height. The temporal change analysis of SSHPI suggests that TC wind intensity and size during landfall time frame have become stronger and larger, respectively, corresponding to increasing storm surge magnitudes from 1980 to 2019. The increased occurrence frequency of TCs with more northeastward tracks is another factor that may have contributed to the increased surge hazards around Tokyo. Tokyo area is likely to experience increasing numbers of extreme storm surge events in the future, if, the current increasing tendency continues.
\end{abstract}

Keywords tropical cyclone; storm surge; trend analysis; hazard potential index; coastal flooding; 


\section{Introduction}

Tropical cyclone (TC)-generated storm surge is one of the most deadly and costly global hazards. In the last two decades, Hurricane Katrina (2005), Cyclone Sidr (2007), Cyclone Nargis (2008), and Typhoon Haiyan (2013) have each caused more than 1,000 fatalities, many of which were the direct result of storm surges (Esteban et al. 2015). Although extreme storm surges do not occur often, the related damage and impacts can be enormous in densely populated urban areas. For example, Hurricane Sandy (2012) inflicted a catastrophic storm surge of $\sim 2.7 \mathrm{~m}$ and resulted in $\$ 50$ billion losses, particularly from storm surge along the mid-Atlantic coast, including the New York City metropolitan area (Blake et al. 2013). Typhoon Jebi in 2018 caused large-scale inundation in Osaka Bay, Japan, and the Kansai-Osaka International Airport was entirely inundated, which resulted in USD 2 billion in damages (Anh et al. 2019). Recent studies have suggested that the number of residents in coastal urban areas and the number of individuals exposed to flooding from once in 100-year storm surge events will continue to increase in the future (Nicholls and Cazenave 2010; Brown et al. 2013; Hallegatte et al. 2013; Neumann et al. 2015). Therefore, it is of great importance to understand whether any changes in storm surge hazards affecting large cities have occurred in recent years, despite the relatively infrequent occurrence of major storm surge events.

Analyzing the changes in storm surge trends in a certain location helps to assess whether coastal flooding risk reduction efforts are effective. Therefore, previous studies have analyzed changes in historical surge magnitudes in a specific location or globally. Several of these studies have concluded that surge levels are increasing over time. For example, Woodworth and Blackman (2004) and Menéndez and Woodworth (2010) analyzed storminduced abnormal sea-level changes by using a global tide gauge dataset. They concluded that many of the gauges showed significant increases in abnormal sea levels since 1970. Bromirski et al. (2003) found a significant increasing trend in extratropical surges in San Francisco since 1950. Church et al. (2006) observed an increase in the frequency of highwater levels (storm surges plus mean sea-level rise) after 1950 by using data from two tide gauges on the eastern and western Australian coasts. Although these studies have confirmed that mean sea-level rise, interannual, and decadal variations are the main factors contributing to the increase in maximum surge height, changes in TC characteristics such as intensity, track, size, and translation speed are also capable of modulating the surge hazard potential (Irish et al. 2008; Sebastian et al. 2014; Islam and Takagi 2020a, 2021).

Various indexes have been used to characterize TC activity, including annual storm counts, intensity, categories (Simpson 1974; Webster et al. 2005), and the accumulated 
cyclone energy (ACE) index (Bell et al. 2000). Some of the index-based analyses have exhibited excellent performances in explaining variations in TC activity trends on global and regional scales. For example, Emanuel (2005) showed that the TC power dissipation index (PDI; destructive potential of TCs) is positively correlated with the increase in sea surface temperature since the 1970s, where PDI is an aggregate of storm intensity, frequency, and duration. Emanuel (2005) also argued that PDI is a better indicator of TC threat than storm frequency or intensity alone. Utilizing the ACE index, similar to the PDI, Camargo and Sobel (2005) showed that there is a tendency in El Niño years toward TCs that are both more intense and longer-lived than in La Niña years in the Western North Pacific (WNP) basin from 1950 to 2002.

To improve the prediction accuracy of previous studies, Islam et al. (2021) statistically developed a storm surge hazard potential index (SSHPI) for estimating TCinduced maximum surge levels at a coast. SSHPI can provide an instantaneous measure to quantify the relative magnitude of a peak surge potential and advance TC measures (i.e., early warning, evacuation decision), akin in philosophy to the Saffir-Simpson Hurricane Wind Scale (SSHWS) (Saffir 1973; Simpson 1974). Although numerical surge modelling is the most sophisticated, advanced, and reliable method to forecast surge catastrophe, constraints related to TC forecast track information (i.e., landfall location and timing, approach angle, intensity, size) remain a major obstacle to a reliable operational surge forecast (Japan Meteorological Agency 2019) (hereafter Japan Meteorological Agency is abbreviated as JMA). As the degree of unusual characteristics of a TC increases, numerical surge forecast tends to underestimate the severity of a surge event (World Meteorological Organization 2011). Nevertheless, several practical solutions such as analytical, graphical (nomograms), empirical, and statistical approaches (i.e., SSHPI) can supplement numerical surge models (World Meteorological Organization 2011).

A retrospective analysis of SSHPI using data from 1978-2019 in Japan suggests that this index captures historical events reasonably well. The SSHPI has two major advantages: it explains the surge hazard potential for a TC that vary in size and speed and decreases numerical computational requirements. It also infers that a surge estimation derived from using only intensity information provides less information on the overall surge hazard than the full form of SSHPI (see Section 2 for the definition of SSHPI). Therefore, assessing whether other factors influence storm surge hazards over time at a specific location is also necessary. Specifically, this allows us to apply a surge index, i.e., SSHPI to explain temporal variations of surge hazards.

The WNP basin is the most active area on Earth for TCs, as approximately one-third 
of the world's TCs develop in the region (Elsner and Liu 2003). Tokyo is one of the largest and busiest cities in this region (United Nation 2018) where TC-induced storm surge poses a considerable threat to millions of coastal inhabitants (Islam et al. 2018). Swiss $\operatorname{Re}$ (2013) ranked 616 cities worldwide in terms of their potential risks for natural disasters, including TCs and storm surges, and reported that the Greater Tokyo Area is subject to the highest risks. Although Tokyo is prone to the effects of TCs, the TC landfall frequency around Tokyo is not very high compared to that of southwestern Japan (Islam and Takagi 2020a). Nevertheless, strong TCs sometimes reach around Tokyo, causing billions of dollars in damage to the city's infrastructure (JMA 2020a). Among the major TCs that have directly affected Tokyo over the past century, a TC in 1917 (known locally as Typhoon Taisho) was the most devastating. The storm surge induced by this typhoon claimed 1,301 lives, destroyed 43,083 houses, and swept away 8,220 marine vessels (Omori 1918).

In modern times, although, most of the coastal areas of Japan including those of Tokyo are protected from storm surges by coastal dikes, the return period of their design high tide level has not been evaluated accurately because of short period of tidal observations (Torii and Kato 2004). In addition, it remains unclear whether overtopping of the dikes would lead to coastal flooding because current dikes did not perfectly resist overtopping against TC-induced high waves (Takagi and Takahashi 2021). Thus, there is an uncertainty regarding whether urban waterfronts of Tokyo and its neighboring cities are sufficiently resilient against future powerful TCs (Islam et al. 2018). Concerns about TCs and storm surge impacts have increased since Typhoon Faxai and Typhoon Hagibis hit the Greater Tokyo Area in 2019. These two typhoons caused severe coastal damage and were classified as the strongest typhoons since the JMA typhoon database was created in 1951 (Shimozono et al. 2020; Takagi et al. 2020). Yamaguchi and Maeda (2020a) showed that the number of TCs, including stronger storms approaching the southern coast of Japan, including Tokyo, has a decadal increasing trend since 1980. They also determined that the translation speeds of TCs have decreased from 1980 to 2019, which indicates that Tokyo and its surroundings experienced TC influences of a longer duration over time (Yamaguchi and Maeda 2020b). These recent studies and TC events raise questions as to whether the magnitude of the storm surge that has affected Tokyo and its neighboring cities has increased recently and whether changes in the storm surge hazard potential are larger than previously determined. Currently, there is no study that has examined the influence of surge hazard potential and long-term storm surge observations around Tokyo.

This study examines changes in storm surge hazards around Tokyo (see Section 2 for the definition of target area) since 1980 in terms of temporal variations in storm surge 
heights and analyzes the SSHPI to investigate factors that influence surge magnitudes. We also inspected changes in the TC tracks and their potential influence on storm surge variations. We used tidal records from ten tide stations and best-track information for TCs that made landfalls around Tokyo.

\section{Data and Methods}

In this study, we considered a period spanning from 1980 to 2019 and obtained TC best track data from the JMA archives, including data pertaining to TCs that originated in the WNP and made landfalls around Tokyo (JMA 2020a). The best track data acquired during the pre-satellite era (i.e., before 1980) contain heterogeneities and large uncertainties in data quality (Chan 2019; Moon et al. 2019) and therefore were ignored. Although the time period processed was relatively short, the period of 1980-2019 was the longest period covered by the JMA best track dataset that has uniform data quality. Data collection was limited to TCs that made landfalls within $300 \mathrm{~km}$ of Tokyo (latitude: $34^{\circ}-37^{\circ} \mathrm{N}$, longitude: $137^{\circ}-141^{\circ} \mathrm{E}$; Fig. 1$)$ with a maximum sustained wind speed $\left(V_{\max }\right)$ of greater than $17 \mathrm{~m} \mathrm{~s}^{-1}$ (33-kt). Although the primary focus of this study is to deal with storm surges in Tokyo, the justification for adopting a distance threshold is twofold. First, the JMA operationally considers any TC with a tropical storm intensity or stronger to be approaching Japan when the central position of the TC is within $300 \mathrm{~km}$ of any of the JMA meteorological offices (JMA $2020 b$ ). Second, the number of TCs ( $\left.V_{\max }>33-k t\right)$ that made landfall in Tokyo Bay (Fig. 2) from 1980 to 2019 is just eight (JMA 2020a), which is insufficient for conducting temporal change analysis of storm surge. Nonetheless, six of the top ten storm surges in Tokyo Bay were not due to direct TC landfalls in Tokyo Bay, but those that made landfall more than 50 km southwest of Tokyo Bay (Islam and Takagi 2020a). Therefore, the analyses presented in this study apply to Tokyo and its neighboring coastal areas (i.e., Hamamatsu, Shizuoka, Shimoda, Katsuura, and Choshi; Fig. 3). TCs are not always powerful (i.e., tropical depressions) and may not produce noticeable storm surge; thus, it would be more meaningful to focus on tropical storms (34-kt $\left.\leq V_{\max } \leq 63-\mathrm{kt}\right)$ or stronger TCs (i.e., category 1, 2 in SSHWS) for disaster risk management. Based on these three criteria, 36 TCs were selected for analysis (Fig. 1). These TCs were further divided into two categories based on their landfall locations: open coastlines (directly facing the Pacific Ocean) and bay areas (regions surrounded by two land areas that form a concave section of coastline). Of the 36 TCs, 10 made landfalls on open coastlines. The remaining 26 TCs made landfalls between open coastlines and bay areas and affected both regions. Among the 36 TCs, 19 and 12 TCs impacted more than one tidal station located on the open coastlines and bay areas, 
respectively. As a result, there were 72 and 90 available storm surge cases for open coasts and bay areas, respectively, for a total of 162 cases.

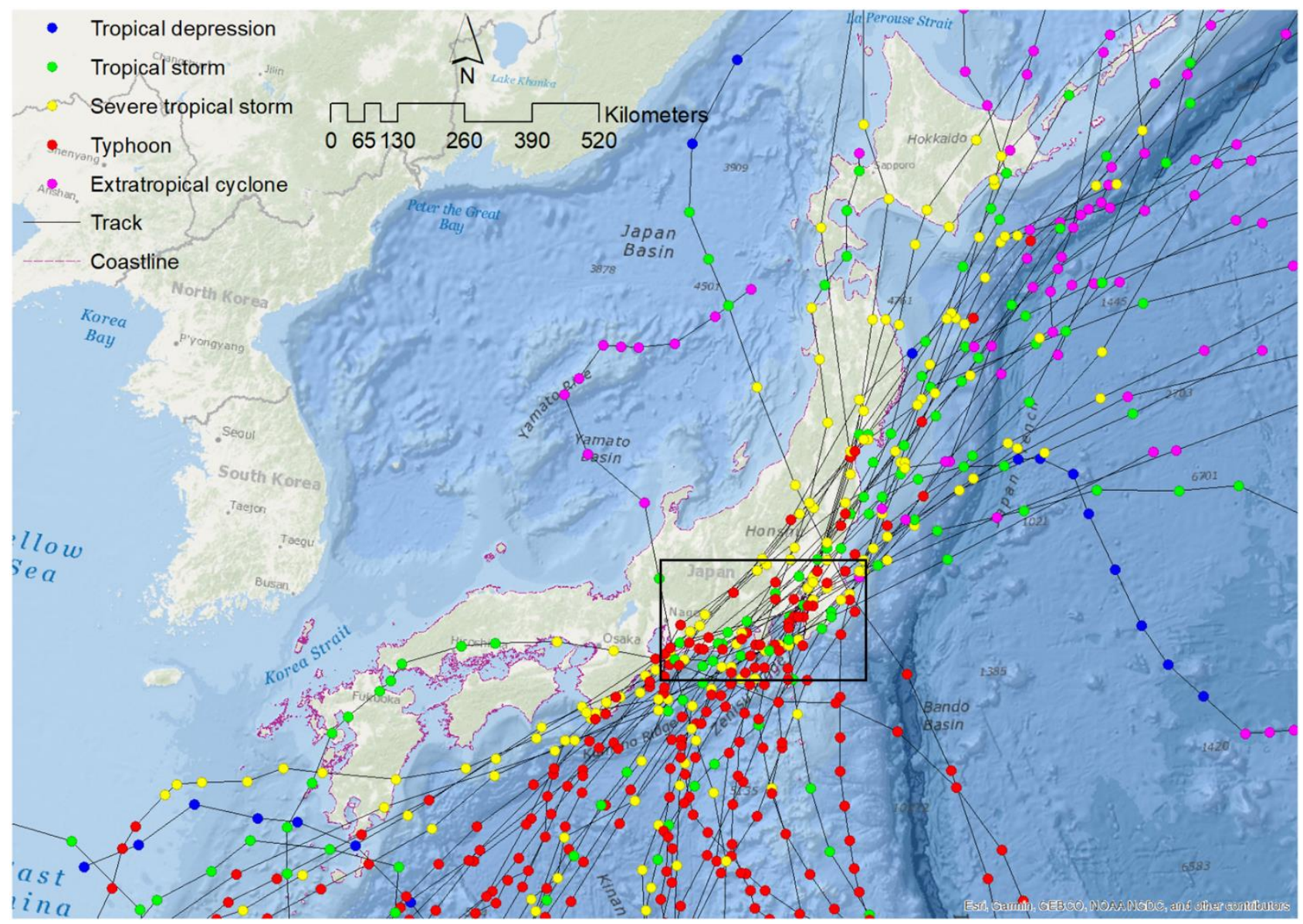

Fig. 1 All TCs that made landfall (as per the criteria considered for the selection of TC) along the coasts of Tokyo and its neighboring cities in 1980-2019 (JMA, 2020a). The black-colored box indicates the area of interest.

We analyzed best track TC central positions, intensities, sizes, and translation speeds at the landfall time frame $(T)$ because storm surge tends to be amplified at the time of landfall. However, TC characteristics during the landfall time frame are not necessarily the most adverse condition to cause the largest storm surge on coasts. For example, storm surges would take the largest value when the TC track is closer to the bay. In this study, we considered TC landfall time rather than the time closest to each tide station located at open coasts and bays as a representative condition for causing peak surge because, (a) TC characteristics (i.e., intensity, size, translation speed), after landfall, differ from those over the ocean. Thus, the TC information over land is considered less reliable (Huang et al. 2021). (b) Although the recent TC best track contains more detailed information about when a TC approaches the land, the JMA best track historically has provided TC information at every six-hour intervals. It is difficult to identify the time of closest approach to a station with the 6- 
hour interval data (c) In the current dataset, 26 of 36 TCs affected both open coasts and bays, and storm surge information was recorded for more than one tidal station for those TCs. Thus, a unique characteristic (i.e., landfalling TC intensity) for each storm can provide a simple basis for statistical analysis.

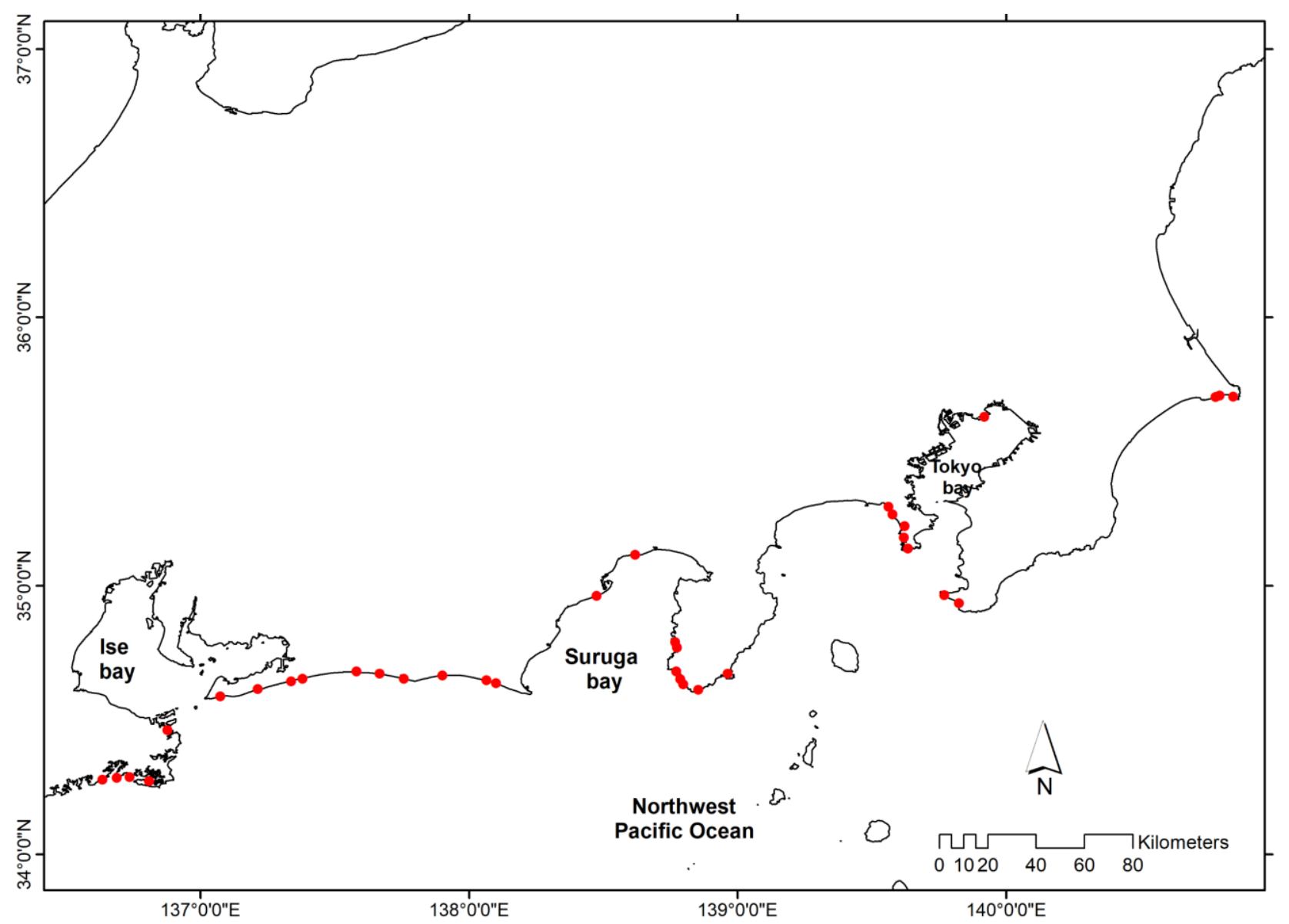

Fig. 2 TC landfall points (red dots; as per the criteria considered for the selection of TC) along the coasts of Tokyo and its neighboring cities in 1980-2019.

According to the JMA (2020c) landfall occurs when the center of a TC reaches the coastline of the mainland (Honshu, Hokkaido, Kyushu, Shikoku) in Japan. We detected the approximate landfall point at which a TC track intersects a coastline by using a vector data provided by the Geospatial Information Authority of Japan (2021). Figure 2 shows TC landfall points $(n=36)$ along the coasts of Tokyo and its neighboring cities. The translation speed at time $T$ ( $T=$ landfall time frame) was calculated using the TC central positions at $T$ and $T$ - 6 hours. Among the 36 TCs, translation speed, intensity, and size data for six TCs were not available at $T$, estimations for the six TCs were obtained via linear interpolation of the available data from immediately before and after landfall. The bathymetry of the target region was obtained from the Japan Oceanographic Data Center (JODC), Japan Coast Guard (JODC 2020a). 

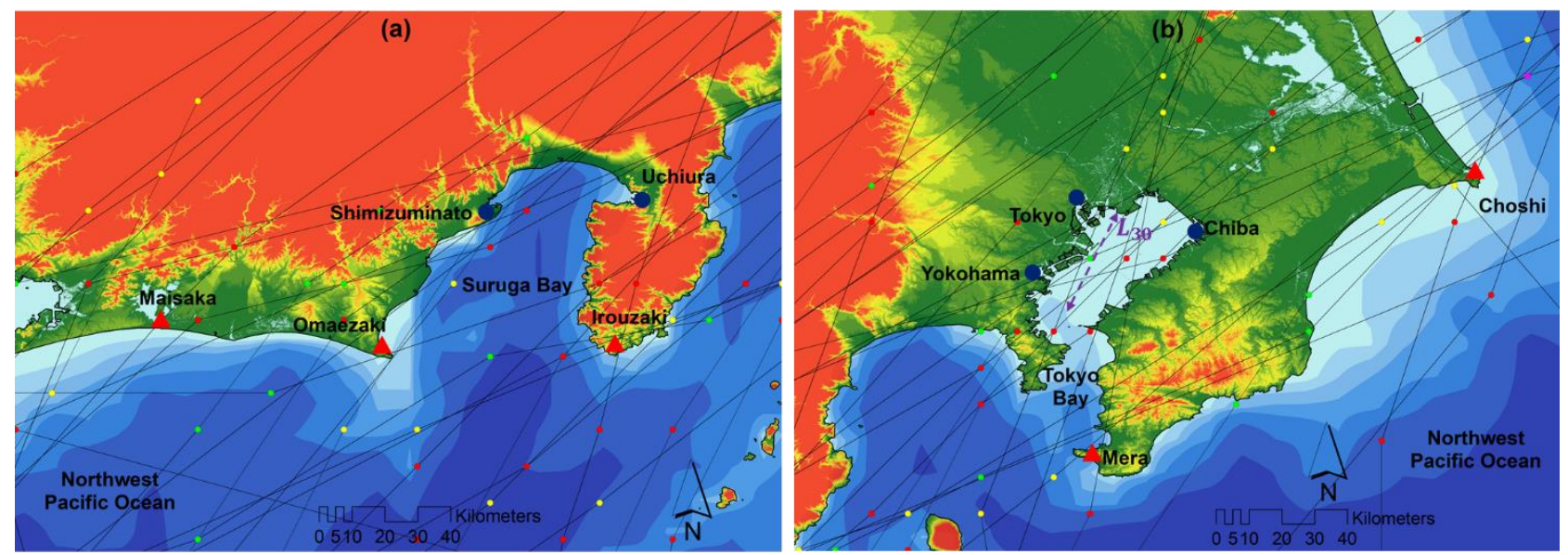

\section{$\operatorname{DEM}(m)$}

Bathymetry (m)

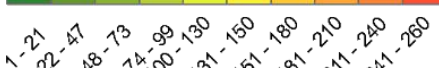

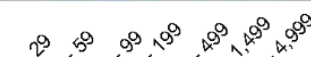

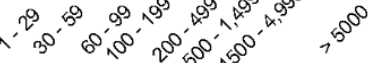

Observed tide station (bays) Tropical cyclone track

- Tropical depression - Tropical storm

Severe tropical storm - Typhoon Extratropical cyclone

Fig. 3 Location map of observed tide stations (a) Maisaka, Omaezaki, Shimizuminato, Uchiura, and Irouzaki (b) Yokohama, Tokyo, Chiba, Mera, and Choshi (JODC, 2000a; Japan Aerospace Exploration Agency, 2015; JMA, 2020a).

Figure 3 shows the ten JMA and Japan Coast Guard-operated tidal stations (JMA 2020d; JODC 2020b) used to estimate the peak storm surge for each TC. Among many operational stations, data collection was limited to those that satisfied the five criteria: (a) located on an open coastline or in a bay; (b) JMA predicted astronomical tide data were available (JMA 2020e); (c) elevations of the observation reference plane and the astronomical tide table reference plane were available; (d) fell to the right side of a selected TC track and located within the range of radius of $50-\mathrm{kt}$ wind $\left(R_{50}\right.$; during TC landfall time frame); and (e) no data gaps occurred when a TC traversed over the station. Five stations were selected from open coastlines (Maisaka, Omaezaki, Irouzaki, Mera, and Choshi), and five stations were selected from semi-enclosed bays (Shimizuminato, Uchiura, Yokohama, Tokyo, and Chiba). Figure 3 provides details of the selected tidal stations. Notably, wave set-up is often the dominant driver for generating storm surge in some selected tidal stations (i.e., Omaezaki, Irouzaki, Mera); however, this influence was not considered, to keep the analysis simple. Sea surface anomalies were defined as the storm surge magnitude (in $\mathrm{cm}$ in this study) and were estimated by deducting the predicted astronomical tide from the observed storm tide.

The SSHPIs at $T$ for all TCs were calculated to demonstrate how the factors influencing storm surge hazard potentials have changed over the last 40 years. Background information and the effectiveness of the SSHPI for predicting peak surge hazard potential were discussed in Islam et al. (2021). TC best track data were used to calculate the SSHPI 
for each storm. Table 1 shows the predictors used in the SSHPI. The SSHPI incorporates meteorological information, including TC intensity, size, and translation speed, along with coastal geometry (open coasts and bays) and regional scale bathymetry into a single measure of the expected surge hazard potential along the coast (Islam et al. 2021) and it is defined as

$$
\begin{gathered}
\text { SSHPI }=\left(\frac{V_{\text {max }}}{V_{\text {ref }}}\right)^{2}\left(\frac{R_{50}}{R_{\text {ref }}}\right)\left(\frac{S}{S_{\text {ref }}}\right)^{a}\left(\frac{L_{30}}{L_{*}}\right), \\
\frac{R_{\text {ref }}}{R_{\text {r }}}=\left\{\begin{array}{l}
1.5 \quad \text { if } \frac{R_{50}}{R_{\text {ref }}} \geq 1.5 \\
\frac{R_{50}}{R_{\text {ref }}} \text { if } 0.5<\frac{R_{50}}{R_{\text {ref }}}<1.5 \\
0.5 \quad \text { if } \frac{R_{50}}{R_{\text {ref }}} \leq 0.5
\end{array} \quad\left(\frac{S}{S_{\text {ref }}}\right)^{a}=\left\{\begin{array}{cc}
1.5 & \text { if }\left(\frac{S}{S_{\text {ref }}}\right)^{a} \geq 1.5 \\
\left(\frac{S}{S_{\text {ref }}}\right)^{a} & \text { if } 0.5<\left(\frac{S}{S_{\text {ref }}}\right)^{a}<1.5 \\
0.5 & \text { if }\left(\frac{S}{S_{\text {ref }}}\right)^{a} \leq 0.5
\end{array}\right.\right.
\end{gathered}
$$

where, $V_{\max }$ is the maximum sustained TC wind speed $(\mathrm{kt}), R_{50}$ is a measure of the radius

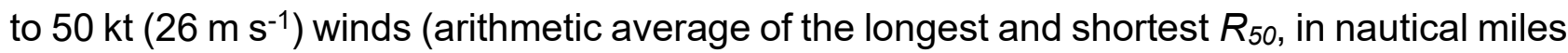
$(\mathrm{nm}), S$ is the translation speed $\left(\mathrm{km} \mathrm{h}^{-1}\right), a$ is the characteristic coastal geometry (for open coasts, $a=1$ and for semi-enclosed bays, $a=-1)$, and $L_{30}$ is the horizontal distance $(\mathrm{km})$ between the shoreline and the $30 \mathrm{~m}$ depth contour. A GIS environment (ArcMap 10.3) was used to measure the closest horizontal distance between each selected tide station and the $30 \mathrm{~m}$ depth contour (i.e., Fig. 3b). $V_{\text {ref, }} R_{\text {ref, }}$ and $S_{\text {ref, }}$ are reference constants used as $50 \mathrm{kt}$ equivalents of the tropical storm category: $95 \mathrm{~nm}$ (historical mean $R_{50}$ at the time of landfall in Japan), and $35 \mathrm{~km} \mathrm{~h}^{-1}$ (historical mean $S$ at the time of landfall in Japan), (Islam et al. 2021). $L$ * was chosen to be $30 \mathrm{~km}$ to make SSHPI roughly equal in magnitude to the peak storm surge height. It was observed that a stationary or very slow-moving TC (i.e., $S=5 \mathrm{~km} / \mathrm{h}$ ) would result in very low SSHPI numbers (using eq. (1)) on the open coast and extremely high numbers in semienclosed bays (vice-versa). TC with a very large size (i.e., $R_{50}=170 \mathrm{~nm}$ ) would also result in very high SSHPI numbers (vice-versa). Although such TCs are infrequent in Japan, but can sometimes occur elsewhere. The upper and lower bound of TC size $\left(0.5 \leq\left(\frac{R_{50}}{R_{r e f}}\right) \leq 1.5\right)$ and forward speed $(0.5$ $\left.\leq\left(\frac{S}{S_{r e f}}\right)^{a} \leq 1.5\right)$ in eq. 1 prevent discrete jumps in SSHPI numbers. In this study, the reference constants ( $V_{\text {ref, }} R_{\text {ref, }}$ and $S_{\text {ref }}$ ) represent a baseline TC event that occurs relatively frequently. This suggests that large (i.e., $R_{50}>95 \mathrm{~nm}$ ) and fast-moving (i.e., $S>35 \mathrm{~km} \mathrm{~h}^{-1}$ ) intense (i.e., $V_{\max }>50 \mathrm{kt}$ ) TCs will generate a larger storm surge along open coasts, whereas bays are more susceptible to large, slowly moving (i.e., $\mathrm{S}<35 \mathrm{~km} \mathrm{~h}^{-1}$ ) intense TCs. Each parameter has a dimension, but the SSHPI is the product of a dimensionless quantity. 
Table 1 TC databases and their scope and limitations based on coverage, resolution, and availability.

\begin{tabular}{|c|c|c|c|c|c|}
\hline Database & Type & \multicolumn{2}{|c|}{ Resolution } & Unit & Data range \\
\cline { 2 - 5 } & & Temporal & Spatial & & \\
\hline $\begin{array}{c}\text { TC 10 minutes - } \\
\text { sustained wind speed }\end{array}$ & Best track & 6 hourly & - & $\mathrm{kt}$ & $1980-2019$ \\
\hline $\begin{array}{c}\text { TC size (radius of 50-kt } \\
\text { wind) }\end{array}$ & Best track & 6 hourly & - & $\mathrm{nm}$ & $1980-2019$ \\
\hline TC forward speed & Best track & 6 hourly & - & $\mathrm{Km} \mathrm{h}-1$ & $1980-2019$ \\
\hline Coastal bathymetry & $\begin{array}{c}\text { Gridded } \\
\text { bathymetry } \\
\text { data }\end{array}$ & - & $500 \mathrm{~m}$ & $\mathrm{~m}$ & $\begin{array}{c}34^{\circ}-37^{\circ} \mathrm{N}, \\
137^{\circ}-141^{\circ} \mathrm{E}\end{array}$ \\
\hline Observed storm tide & - & 1 hourly & - & $\mathrm{cm}$ & $1980-2019$ \\
\hline Predicted astronomic tide & - & 1 hourly & - & $\mathrm{cm}$ & $1980-2019$ \\
\hline Observed storm surge & - & 1 hourly & - & $\mathrm{cm}$ & $1980-2019$ \\
\hline
\end{tabular}

The storm surge and surge hazard potential time series were calculated based on annual mean storm surge heights and annual mean SSHPIs from 1980 to 2019. We divided the 40-year dataset into two sub-periods: 1980-1999 and 2000-2019, hereafter referred to as $\mathrm{P} 1$ and $\mathrm{P} 2$, respectively. The temporal changes in storm surge height and SSHPI were estimated by linear regression. The percentage change was calculated by dividing the difference between the last and first points of the best-fit line by the first point. The two-tailed Student's $t$-test was used to determine if the means of any two sets of data were significantly different. The $p$-values of the regressions and $t$-test statistics were calculated based on the two-tailed $95 \%$ confidence level test.

\section{Results}

\subsection{Observational evidence}

The time series of annual mean storm surge heights is shown in Fig. 4a. A highly significant increase in storm surge height of $+41 \%$ occurred per decade from 1980 to 2019 . Annual mean storm surges of $24 \mathrm{~cm}$ and $55 \mathrm{~cm}$ occurred near Tokyo in P1 and P2, respectively. The difference between the periods is statistically significant at the $95 \%$ level. A similar increasing tendency (+40\% per decade from 1980 to 2019 ) was also observed for the dataset comprising annual peak storm surge heights (Fig. 4b). At least one storm surge event with a peak surge height of $\sim 100 \mathrm{~cm}$ occurred annually near Tokyo since 2011. In terms of the criteria considered in this study (see Section 2 for the definition of the TC landfall), P1 contained 11 years when no identifiable storm surge occurred near Tokyo (1980, 1982, 1984, 1986, 1987, 1988, 1992, 1994, 1995, 1996, and 1999). In contrast, P2 
contained only four years without a storm surge occurrence (2003, 2006, 2008, and 2010). Such differences in the TC landfall frequency appear to contribute to a larger storm surge tendency in P2 than in P1. However, a significant change was also evident in the years with storm surge events. To test the robustness of the statistics presented herein, particularly the outliers, the results were reaffirmed using the $L^{1}$ norm (not shown) in place of the ordinary least-squares $\left(L^{2}\right)$ norm. None of the significant changes from the $L^{2}$ regression was insignificant.

(a)

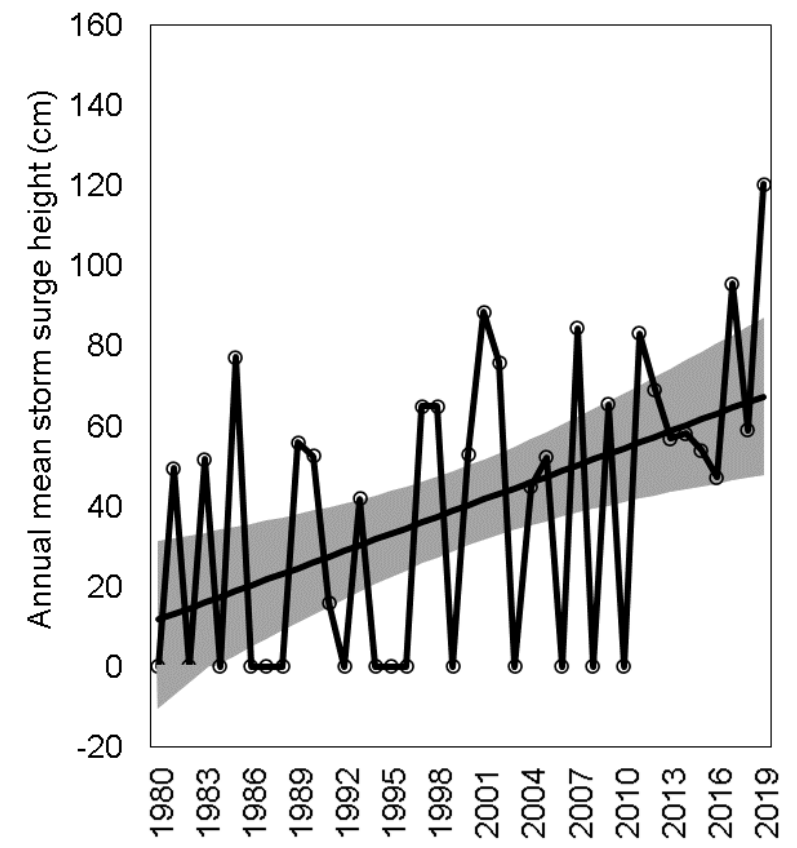

(b)

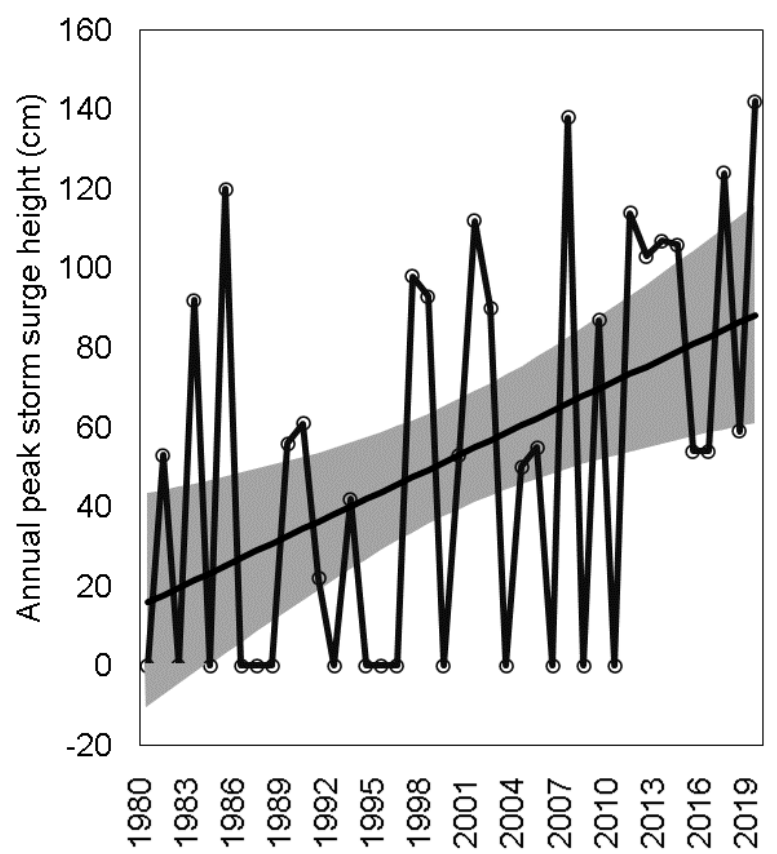

Fig. 4 Time series of (a) annual mean storm surge height (cm); (b) annual peak storm surge height $(\mathrm{cm})$ along the coasts of Tokyo and its neighboring cities over 40 years from 19802019. Gray shading indicates the two-sided $95 \%$ confidence bounds around the linear regression line. The difference in the storm surge height averaged over 1980-1999 and $2000-2019$ is statistically significant at the $95 \%$ level.

The distribution of storm surge events exhibited a clear shift towards greater heights during P2 and the differences were significant throughout most of the distribution (Fig. 5). For example, there was a significantly higher probability of storm surges $>95 \mathrm{~cm}$ during P2, and a significantly higher probability of storm surges $<65 \mathrm{~cm}$ during $\mathrm{P} 1$. In other words, the occurrence frequency of significant storm surges (i.e., $>95 \mathrm{~cm}$ ) in the study area increased in P2 (eight times) than in P1 (two times). 


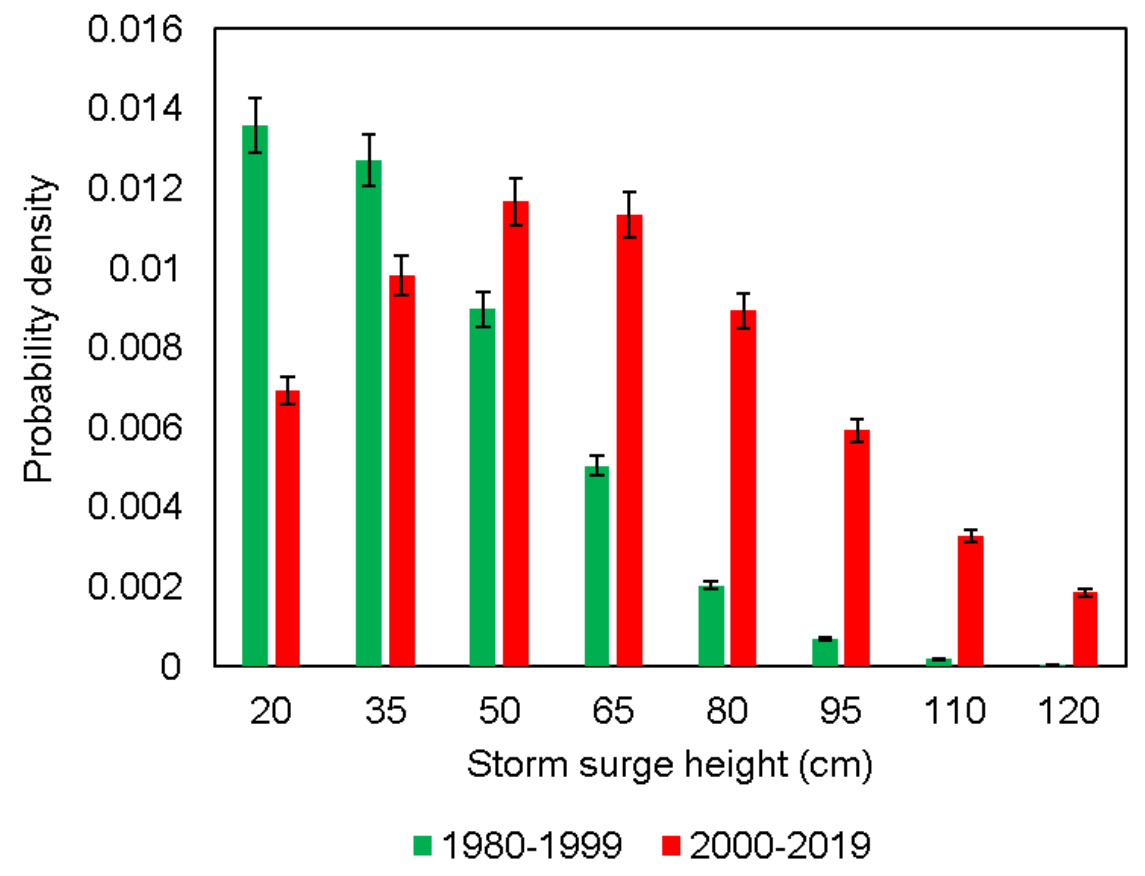

Fig. 5 Change in the annual mean storm surge distribution along the coasts of Tokyo and its neighboring cities. The changes are shown between P1 (1980-1999) and P2 (2000-2019). Error bars show two-sided $95 \%$ confidence intervals.

\subsection{Spatial distribution of storm surge statistics}

Figure 6 shows the spatial distribution of storm surge statistics between P1 and P2 at the ten tidal stations. While an overall increase in storm surge height was evident at all stations, a statistically increasing tendency was more pronounced at four stations (Harumi, Chiba, Yokohama, and Mera) in Tokyo Bay. The magnitude of the change indicates that storm surge heights in Tokyo Bay increased by an average of $+45 \%$ per decade, which is $4 \%$ larger than the overall increase $(+41 \%)$ observed along the coasts of Tokyo and its' neighboring cities (considering all ten stations). Only one case shows the storm surge exceeded $100 \mathrm{~cm}$ in Tokyo Bay during P1, in contrast with six events recorded during P2, including four events in the last 10 years. Additionally, similar significant increases in storm surge heights were evident along open coasts $(+33 \%$ per decade (not shown), considering five stations on open coastlines) and in semi-enclosed bays ( $+44 \%$ per decade (not shown); considering five stations in bays). 


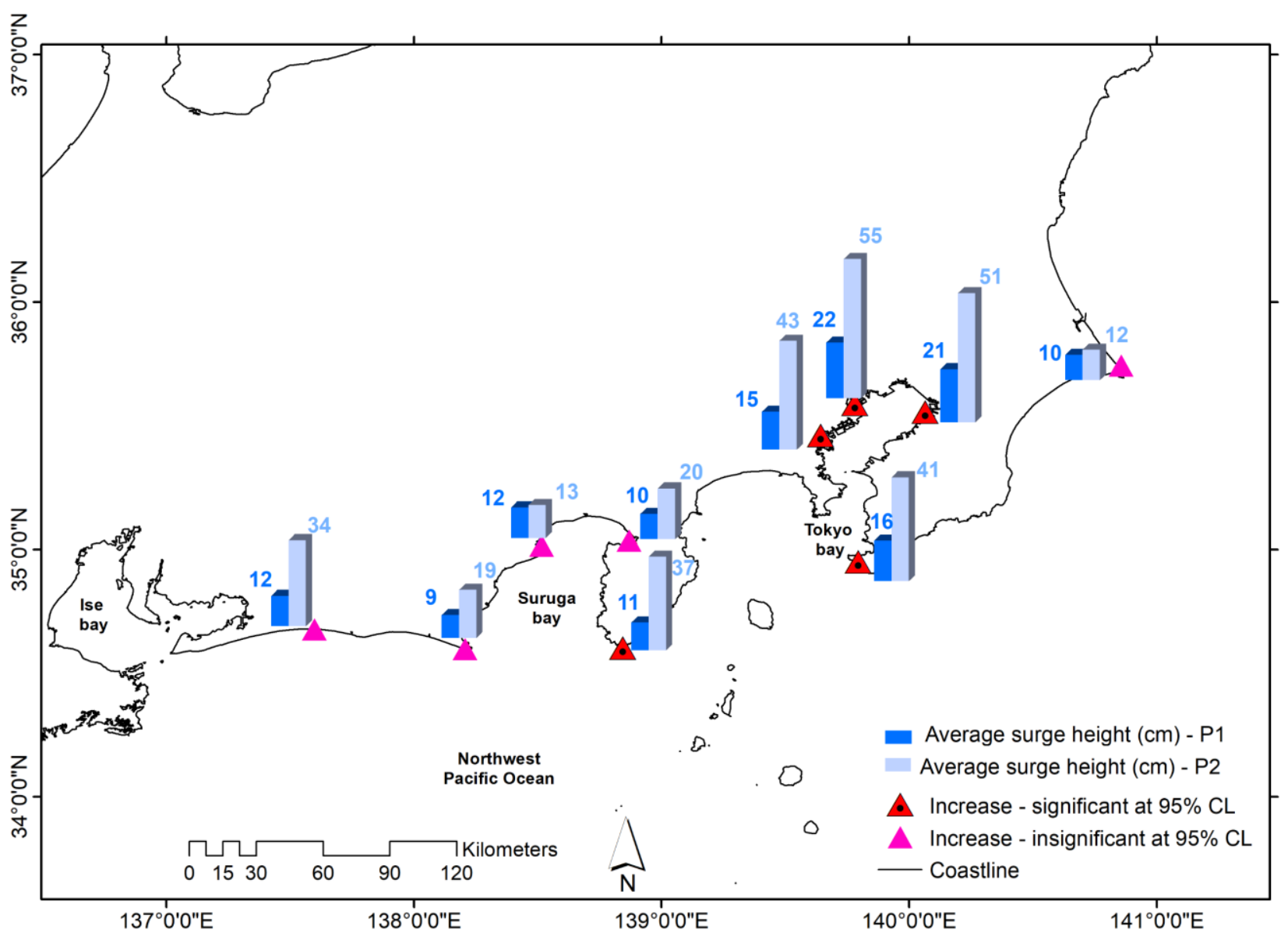

Fig. 6 Spatial distribution of storm surge change statistics between P1 (1980-1999) and P2 (2000-2019) along the coasts of Tokyo and its neighboring cities.

\subsection{Changes in TC parameters influence storm surge}

Table 2 shows the differences in the TC parameters that can influence surge magnitude, including wind speed, size, and translation speed, between P1 and P2. Note that these factors were calculated for the landfall time frame of each TC that made landfall around Tokyo (see Data and Methods for the definition of TC landfall). TCs during P2 had more influences on greater storm surge generation than those in P1 due to stronger wind speeds and larger sizes. Differences in wind speed and size between P1 and P2 were statistically significant at the $95 \%$ level. Although landfalling TC translation speeds during $\mathrm{P} 2$ decreased by $\sim 5 \%$ compared with $\mathrm{P} 1$, this difference was not statistically significant. This finding was in contrary to the findings of Yamaguchi and Maeda (2020b), who found a significant decrease (36\%) in the translation speed of approaching TCs in the Tokyo area. However, Yamaguchi and Maeda's (2020b) findings were valid for the selected approaching TCs (including those that did not make landfall) in September over the last 40 years (19802019) and in this study, we considered all the TCs that made landfall in any month (the selected 36 TCs made landfall between June to October) during the same 40-year period. 
Table 2 TC meteorological parameter characteristics during landfall time frame between 1980-1999 and 2000-2019, with the $p$-value for the two-tailed Student's $t$-test assessing the statistical significance of their difference.

\begin{tabular}{|c|c|c|c|}
\hline TC parameter & $\mathbf{1 9 8 0 - 1 9 9 9}$ & $\mathbf{2 0 0 0 - 2 0 1 9}$ & $\boldsymbol{p}$-value \\
\hline Maximum sustained wind speed (kt) & 55 & 64 & 0.004 \\
\hline Radius of 50-kt wind (nm) & 50 & 65 & 0.01 \\
\hline Translation speed $\left(\mathrm{km} \mathrm{h}^{-1}\right)$ & 43 & 41 & 0.075 \\
\hline
\end{tabular}

(a)

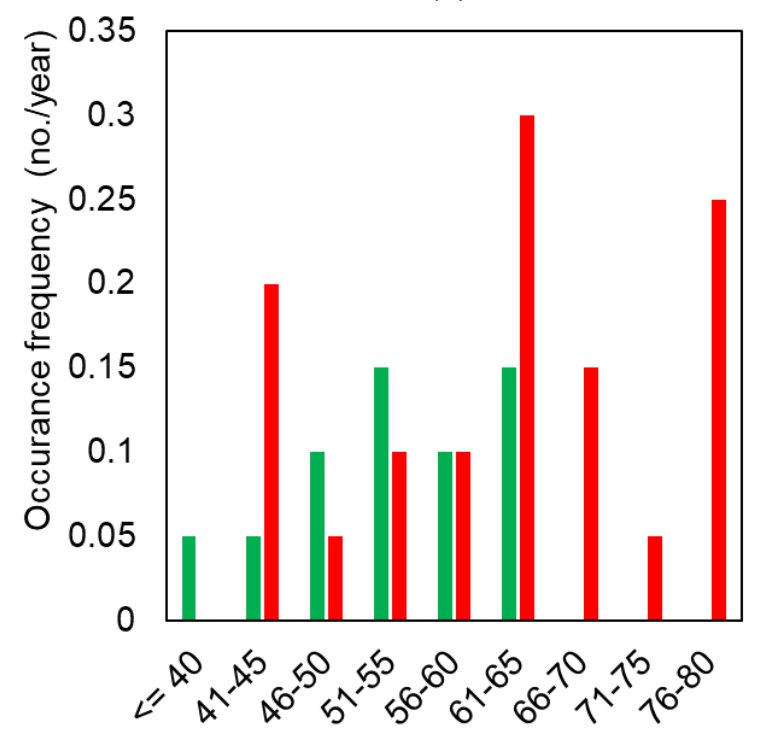

Wind speed during landfall (kt)

- 1980-1999 = 2000-2019 (b)

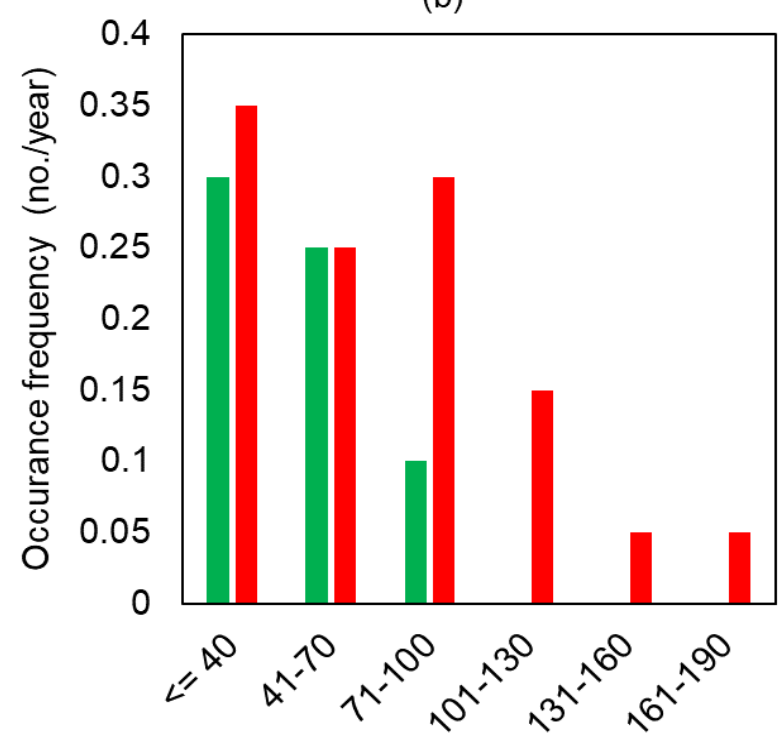

Radius of 50-kt wind during landfall time $(\mathrm{nm})$

" 1980-1999 - 2000-2019

(c)

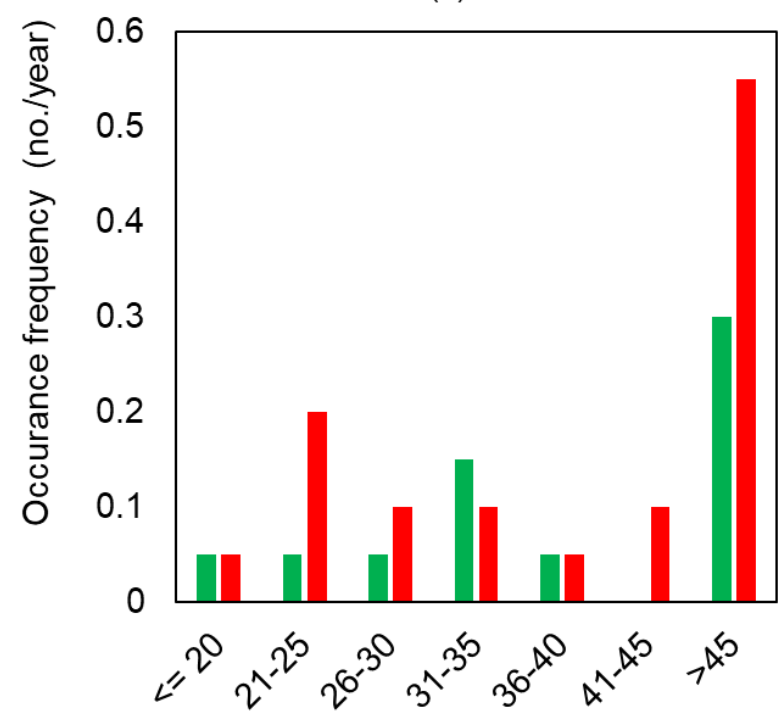

Translation speed during landfall time $\left(\mathrm{km} \mathrm{h}^{-1}\right)$

" 1980-1999 = 2000-2019

Fig. 7 Average annual number of landfalling TC (as per the criteria considered for the selection of TC) along the coasts of Tokyo and its neighboring cities in 1980-2019 as a 
function of the (a) maximum sustained wind speed (kt); (b) radius of 50-kt wind (nm); (c) translation speed $\left(\mathrm{km} \mathrm{h}^{-1}\right)$ at the landfall time frame.

Figure 7 shows the occurrence frequency of the TCs that made landfall around Tokyo as a function of their wind intensities, sizes, and translation speeds at the time of landfall. Note that the occurrence frequency is not equivalent to the total number of TCs. This observation indicated that the number of landfalling TCs that fulfilled the criteria used in this study ( $n=36$; see Data and Methods for the definition of TC selection). The numbers of occurrence frequencies of TCs with $V_{\max }>60$-kt during P1 and P2 were 0.15 and 0.75 , respectively (Fig. 7a). Thus, there were five times more chances for a TC to affect Tokyo during P2 than during P1; thus, the frequency of strong TCs has increased over time. This finding is consistent with those of Yamaguchi and Maeda (2020a), who found that the frequency of strong TCs with a central pressure $<980 \mathrm{hPa}$ that approached the Tokyo area increased by 2.5 times. Figure $7 \mathrm{~b}$ shows that the numbers of occurrence frequencies during $\mathrm{P} 1$ and $\mathrm{P} 2$ in the $R_{50} \leq 40 \mathrm{~nm}$ bin were 0.3 and 0.35 , respectively. In contrast, TCs with $R_{50}$ $>70 \mathrm{~nm}$ had five times more chance of affecting the Tokyo area during P2 compared with P1. No clear changes were observed in the occurrence frequencies of faster or slower TCs during the last 40 years (Fig. 7c). It needs to be noted that the statistics presented in Fig. 7 are based on low- frequency TC events (lower than one per year); therefore, the likelihood of overestimation or underestimation estimation is not negligible.

\section{Discussion}

\subsection{Changes in storm surge hazard potential}

The purpose of this study was to determine whether there have been significant changes in the storm surge hazard around Tokyo in the last 40 years in terms of the storm surge magnitude and TC parameters that can influence the surge hazard. In particular, it is important to quantify the contribution of TC parameters on the increasing surge magnitude as shown in Section 3. Therefore, we applied SSHPI to demonstrate whether a similar increasing tendency is reproduced with the index and whether it can explain the possible contribution of each TC parameter in changing surge hazards.

Figure 8 shows the annual mean SSHPIs (Eq. (1)) at the time of TC landfall and the annual mean storm surge heights for Tokyo. SSHPI constitutes surge sensitive TC meteorological parameters; thus, it can be used to quantify the hazardous surge events by varying the parameters. For example, there is an apparent strong relationship between the two-time series (annual mean SSHPI and annual mean storm surge heights; $R^{2}=0.68$ ), 
suggesting that SSHPI is strongly correlated with storm surge magnitude. This result supports the analysis by Islam et al. (2021), in which SSHPI was strongly correlated with actual surge heights observed throughout Japan. The SSHPI time series exhibited an evident increase of $+63 \%$ per decade from 1980 to 2019 . Annual mean SSHPIs of 0.21 and 0.71 were obtained for $\mathrm{P} 1$ and $\mathrm{P} 2$, respectively. The difference between these SSHPIs is statistically significant at the 95\% level, indicating that the increase in SSHPI during P2 (more than three times) is unusual. A similar tendency was observed for both open coastlines and semi-enclosed bays (not shown). These findings are consistent with the observed storm surge statistics, as described in Results.

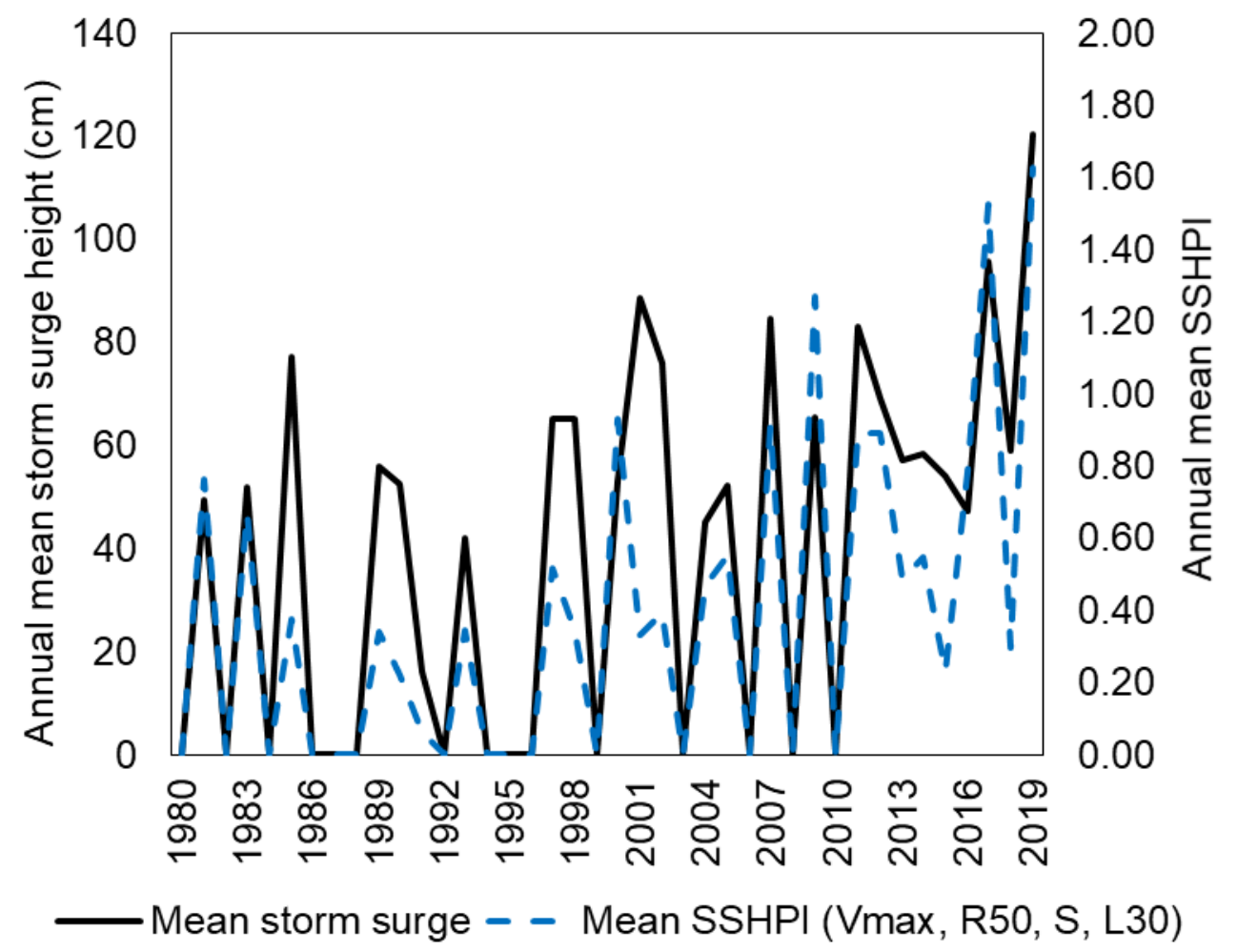

Fig. $8 \mathrm{~A}$ measure of the storm surge hazard potential by tropical cyclones affected Tokyo and its neighboring cities compared to annual mean storm surge height in 1980-2019.

Table 3 presents our attempt to quantify the contributions of TC meteorological parameters to the storm surge variations shown in Figure 4. We assumed that only one of the SSHPI parameters changed between P1 and P2, and maintained the other parameters' value at their averages from P1 (Table 2). Changes in TC intensity and size contributed 35\% and $32 \%$, respectively, to the overall increase in surge height. Furthermore, their joint contribution may be responsible for as much as $79 \%$ of surge variance. Figure 9 shows similar findings by comparing surge height with the time series diagram of the surge index that reduces the predictors from the SSHPI into three patterns: (a) $V_{\max }$; (b) $V_{\max }$ and $R_{50}$; 
and (c) $V_{\max }, R_{50}$, and $S$. Table 3 and Fig. 9 indicate that changes in TC intensity $\left(V_{\max }\right)$ may have played the most significant role in the increase of storm surge magnitudes observed over the last 40 years, followed by changes in TC size $\left(R_{50}\right)$. This finding is consistent with the findings of Islam and Takagi (2020a, 2020c), who numerically showed that, at a constant TC wind intensity, storm surge heights in Tokyo Bay increased linearly as TC size increased. It is possible because a large swath of strong winds can affect a larger ocean area for a longer period of time, inducing larger storm surges.

Table 3 Possible contribution of TC meteorological parameters in storm surge variation observed during 1980-2019. The contribution (\%) is calculated assuming that only one of the TC meteorological parameters included in SSHPI changed between P1 and P2, while maintaining the other parameters value at their averages from P1.

\begin{tabular}{|c|c|c|c|c|}
\hline SSHPI components & $\begin{array}{c}1980-1999 \\
\text { (P1) }\end{array}$ & 2000-2019 (P2) & $\begin{array}{c}\text { Change } \\
\text { parameter } \\
\text { in P2 }\end{array}$ & $\begin{array}{c}\text { Contribution } \\
(\%)\end{array}$ \\
\hline Wind speed (kt) & 55 & 64 & \multirow{3}{*}{ Wind speed } & \multirow{3}{*}{$\sim 35$} \\
\hline Size $(\mathrm{nm})$ & 50 & $\begin{array}{c}\text { Set to the same } \\
\text { value as } P 1\end{array}$ & & \\
\hline Translation speed $\left(\mathrm{km} \mathrm{h}^{-1}\right)$ & 43 & $\begin{array}{c}\text { Set to the same } \\
\text { value as } P 1\end{array}$ & & \\
\hline Wind speed (kt) & 55 & $\begin{array}{l}\text { Set to the same } \\
\text { value as } \mathrm{P} 1\end{array}$ & \multirow[t]{3}{*}{ Size } & \multirow[t]{3}{*}{$\sim 32$} \\
\hline Size $(\mathrm{nm})$ & 50 & 66 & & \\
\hline Translation speed $\left(\mathrm{km} \mathrm{h}^{-1}\right)$ & 43 & $\begin{array}{c}\text { Set to the same } \\
\text { value as } P 1\end{array}$ & & \\
\hline Wind speed (kt) & 55 & $\begin{array}{c}\text { Set to the same } \\
\text { value as } P 1\end{array}$ & \multirow{3}{*}{$\begin{array}{c}\text { Translation } \\
\text { speed }\end{array}$} & \multirow[t]{3}{*}{$\sim 5$} \\
\hline Size $(\mathrm{nm})$ & 50 & $\begin{array}{l}\text { Set to the same } \\
\text { value as } P 1\end{array}$ & & \\
\hline Translation speed $\left(\mathrm{km} \mathrm{h}^{-1}\right)$ & 43 & 41 & & \\
\hline Wind speed $(\mathrm{kt})$ & 55 & 64 & \multirow{3}{*}{$\begin{array}{l}\text { Wind speed } \\
\text { and size }\end{array}$} & \multirow{3}{*}{$\sim 79$} \\
\hline Size $(\mathrm{nm})$ & 50 & 66 & & \\
\hline Translation speed $\left(\mathrm{km} \mathrm{h}^{-1}\right)$ & 43 & $\begin{array}{l}\text { Set to the same } \\
\text { value as } P 1\end{array}$ & & \\
\hline Wind speed (kt) & 55 & 64 & \multirow{3}{*}{$\begin{array}{c}\text { Wind } \\
\text { speed, size, } \\
\text { and } \\
\text { translation } \\
\text { speed }\end{array}$} & \multirow{3}{*}{$\sim 70$} \\
\hline Size $(\mathrm{nm})$ & 50 & 66 & & \\
\hline Translation speed $\left(\mathrm{km} \mathrm{h}^{-1}\right)$ & 43 & 41 & & \\
\hline
\end{tabular}




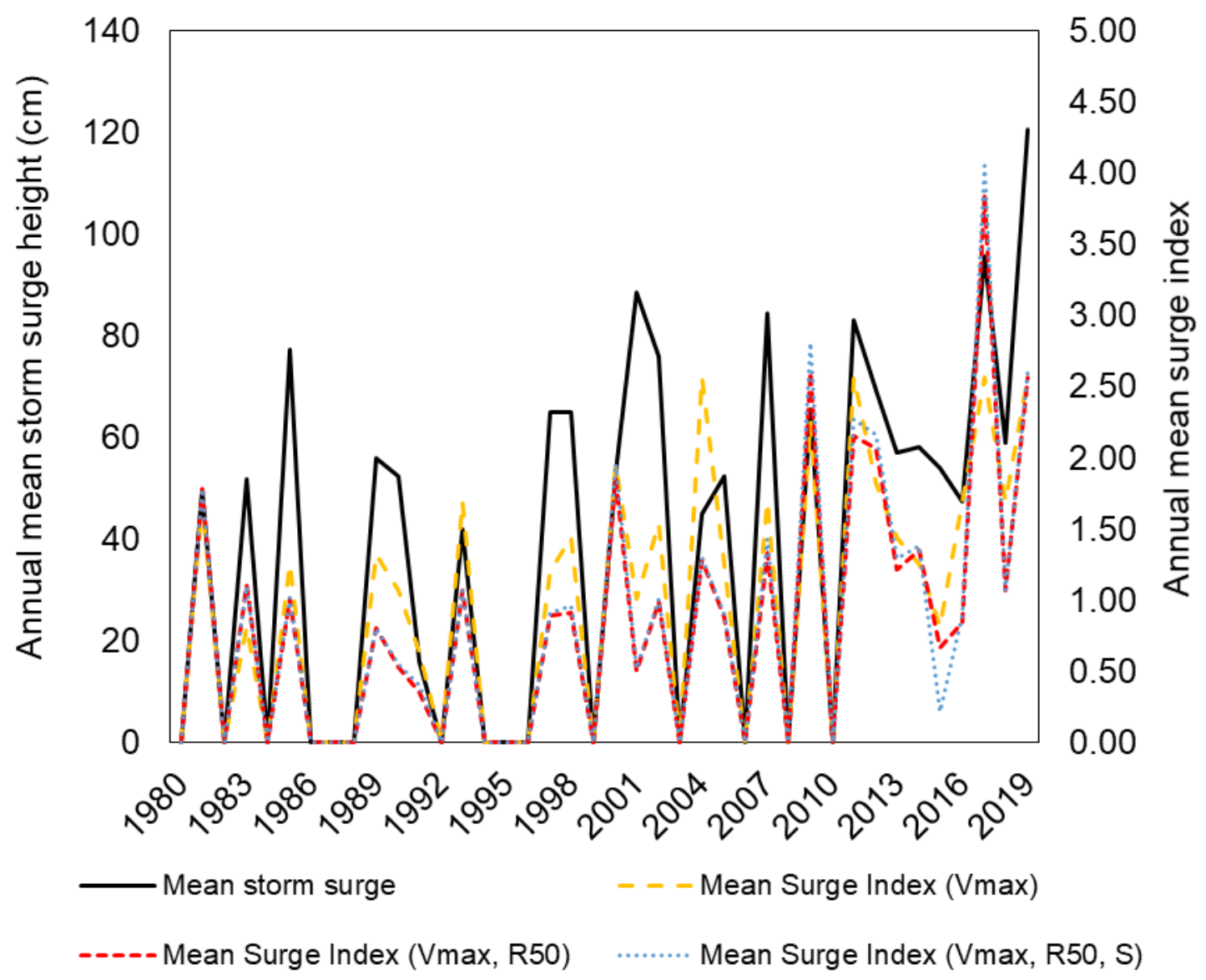

Fig. 9 Possible contribution of TC meteorological parameters in storm surge variation observed along the coasts of Tokyo and its neighboring cities during 1980-2019.

\subsection{Changes in TC track}

We also inferred the reasons for the increase in storm surge magnitude by analyzing the differences in the TC tracks between P1 and P2. Six-hourly TC best track positions, along with intensity information of landfalling TCs, were analyzed at each grid point from $34^{\circ}$ to $37^{\circ} \mathrm{N}$ and from $137^{\circ}$ to $141^{\circ} \mathrm{E}$, at $1^{\circ}$ intervals (Figs. 10a, 10b). The ratios of the changes in landfalling TC frequency for each grid point (i.e., the ratio of the number of TC central positions in $\mathrm{P} 2$ to $\mathrm{P} 1$ ) are shown in Fig. 10c. An overall increase in TC activity is evident in the grids covering Tokyo and its surroundings. One remarkable feature is a statistically significant increase in TC activity close to Tokyo Bay (near $34^{\circ}-36^{\circ} \mathrm{N}, 139^{\circ}-140^{\circ} \mathrm{E}$ ) during $\mathrm{P} 2$ than in $\mathrm{P} 1$. In other words, the occurrence frequency of more northeastward TC tracks that impacted Tokyo's shallow coastal areas (Fig. 3b) increased during P2 than in P1 (Fig. 10c). A significant number of TCs with greater intensities (i.e., $V_{\max } \geq 64 \mathrm{kt}$ ) evidently impacted Tokyo Bay during P2, and such TCs occurred at low-frequencies during P1 (Fig. $10 a, b)$. Although the storm surge increasing tendency is independent of TC frequency (discussed in Section 3), changes in the occurrence frequency of more northeastward TC 
tracks can be regarded as the third most influential factor after $V_{\max }$ and $R_{50}$. Therefore, the large increase in surge magnitude, particularly inside Tokyo Bay (Fig. 6) over the past 40 years, might be attributed to the combined influence of TC intensity, size, and track change.
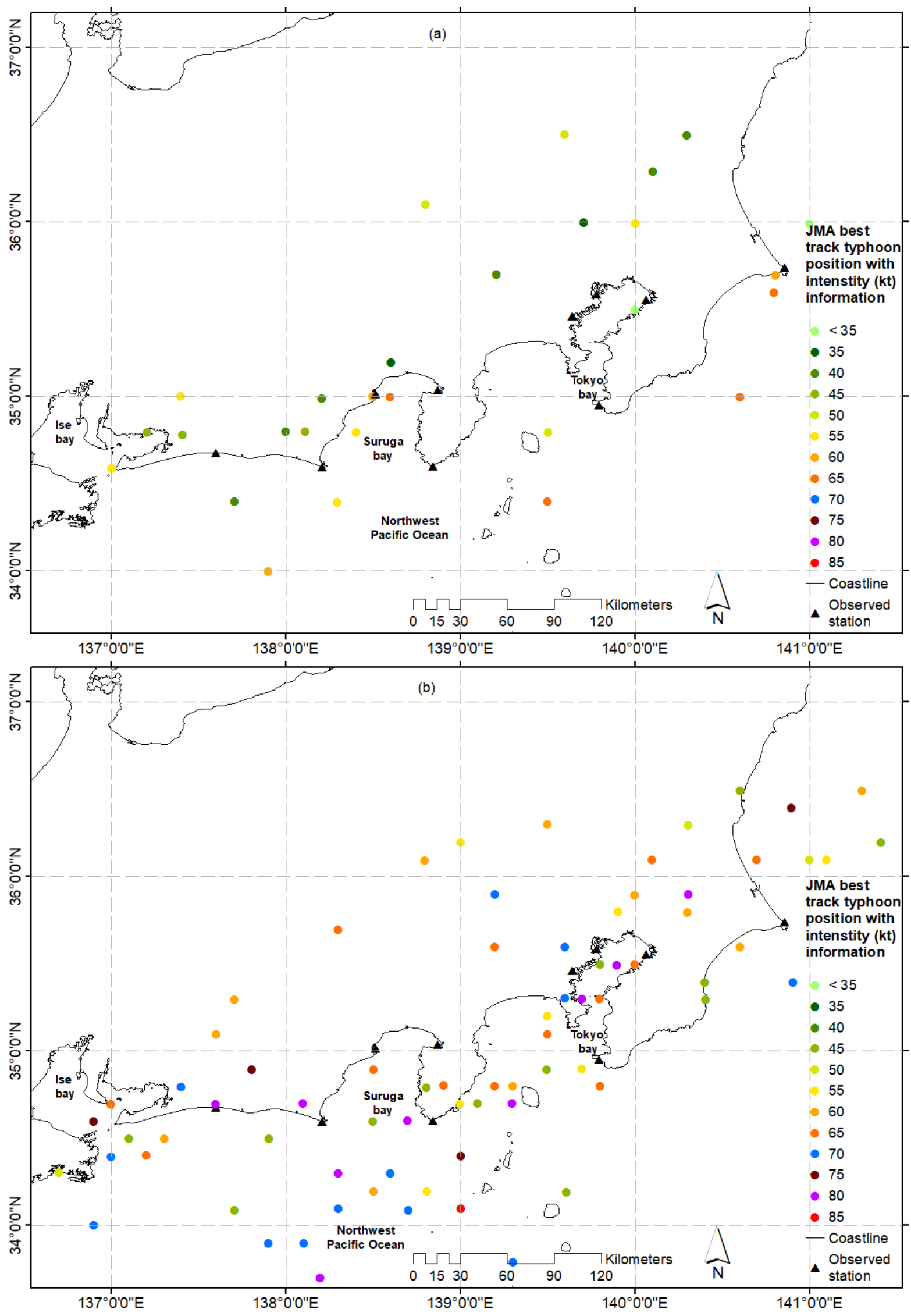


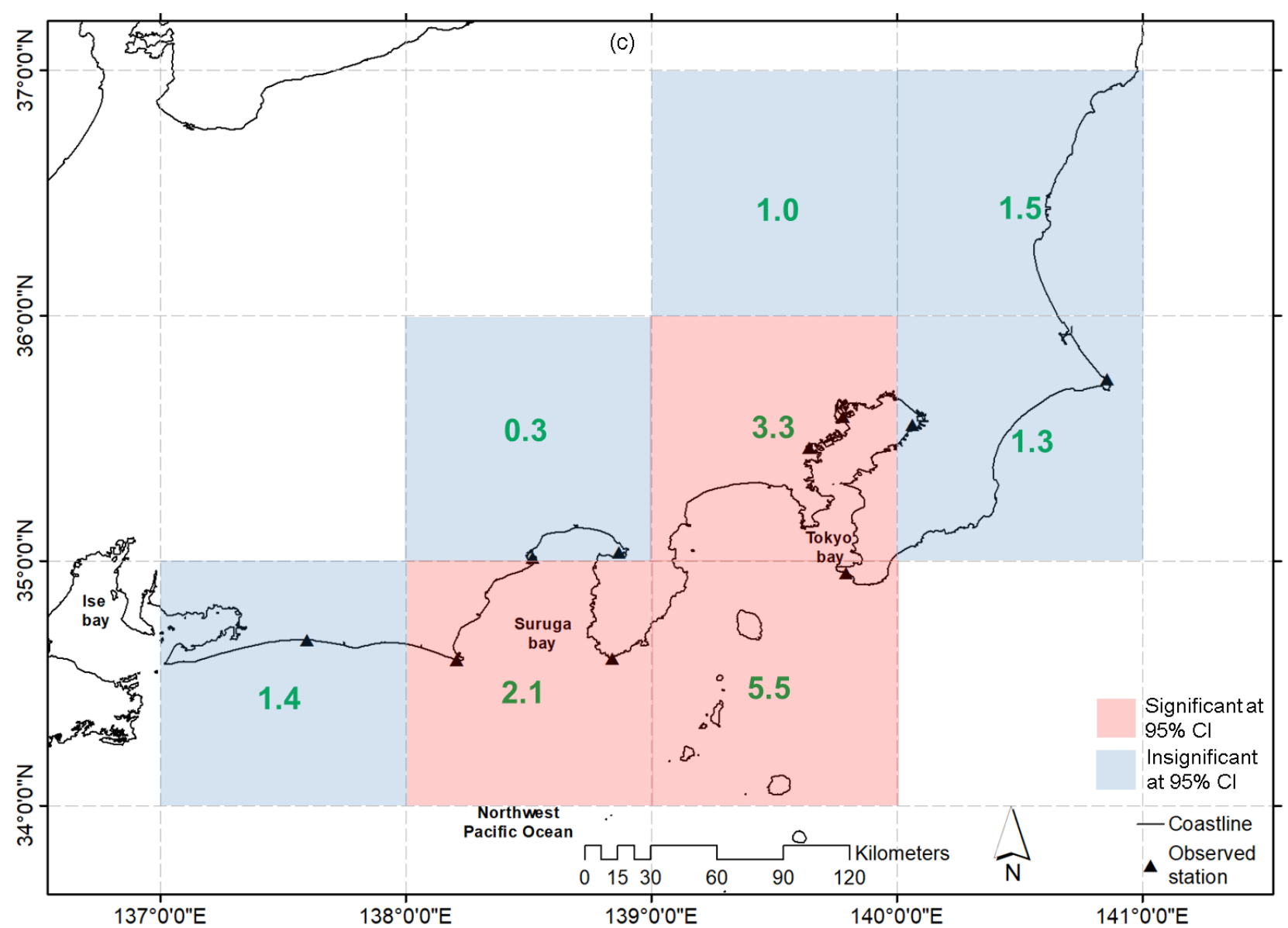

Fig. 10 Landfalling TC six-hourly best track position along with intensity information bounded in latitude by $34^{\circ} \mathrm{N}$ and $37^{\circ} \mathrm{N}$, and longitude by $137^{\circ} \mathrm{E}$ and $141^{\circ} \mathrm{E}$. in (a) $1980-1999$ (P1); (b) 2000-2019 (P2); (c) The ratio of the landfalling TC activity (the number of TCs central position in $\mathrm{P} 2$ divided by that in $\mathrm{P} 1$; green colored number) in each grid.

\section{Summary and Conclusions}

Based on observational data, the present study demonstrates that storm surge heights in eastern Japan, including those in Tokyo, have increased significantly from 1980 to 2019. The SSHPI from 1980 to 2019 increased more than three times from P1 to P2. It also suggests that the changes in both TC intensity and size at the time of landfall played a significant role in increasing storm surge magnitudes. This finding is consistent with the observation where it is shown that TCs have become stronger and larger, respectively during P2 than in P1. The increased occurrence frequency of TCs with more northeastward tracks contributed to the increased surge hazard around Tokyo.

This study suggests that the Tokyo area is likely to experience increasing numbers of extreme storm surge events in the future, if the current increasing tendency continues. The coastal flooding of Tokyo could have affected the Japanese economy substantially because much of the Japanese GDP is concentrated in the Tokyo area. Thus, our findings 
are valuable for disaster risk managers, coastal engineers, climate change scientists, and governmental bodies attempting to mitigate storm surge risk in coastal urban areas. The SSHPI can help explain variations in surge events on regional and local scales, such as Tokyo area targeted in this study.

The analyses presented in this study do not constitute the detection or contributions of global warming and climate change impacts on an increasing storm surge tendency. Although the difference between P1 and P2 could be regarded as a trend associated with global warming, several recent studies have projected with high confidence that sea-level rises that accompany warming will lead to higher storm inundation levels (i.e., Knutson et al. 2019; Knutson et al. 2020; Mori et al. 2021). However, Yamaguchi and Maeda (2020a) reported that this difference may not be distinguishable in the interdecadal variability of such a short period (40 years). In addition, it is known that there are significant interdecadal variations exist in TC activity in the WNP basin (i.e., Chan 2016; Li and Zhou 2018). Thus, further research should include quantitative evaluations of the contributions of global warming and interdecadal variations by using numerical simulations. This study statistically quantifies the contribution of TC meteorological parameters in changing surge hazards. Particularly, we have discussed the possible contribution of TC wind speed, size, and track in changing surge hazards around Tokyo; nonetheless, other factors such as air pressure, wave set-up can also modulate surge hazards. The physical meaning of these influential factors remains unknown. The present analyses can be improved further by improving the current data quality, in time and spatial coverage.

\section{Acknowledgments}

The first author is thankful to the Ministry of Education, Culture, Sports, Science, and Technology (MEXT) of Japan for the provided scholarship to conduct research in the field of disaster risk reduction. This study was conducted while the first author was participating in the internship at Atmosphere and Ocean Research Institute, The University of Tokyo. Authors are grateful to Dr. Munehiko Yamaguchi, Japan Meteorological Agency, for providing the approached TC number information for Tokyo area (1980-2019).

\section{Data availability statement}

Observed storm tide data can be downloaded from the JMA (http://www.data.jma.go.jp/kaiyou/db/tide/genbo/index.php) JODC (https://jdoss1.jodc.go.jp/vpage/tide.html) websites. Predicted tide data can be obtained from the JMA (http://www.data.jma.go.jp/kaiyou/db/tide/suisan/index.php) website. TC best track data can be derived from the JMA (https://www.jma.go.jp/jma/jma-eng/jma- 
center/rsmc-hp-pub-eg/trackarchives.html) website.

\section{Disclosure statement}

No potential conflict of interest was reported by the author(s).

\section{Funding}

This research was funded by the grants awarded to Tokyo Institute of Technology (Japan Society for the Promotion of Science, 16KK0121 and 19K04964). This work was also partially supported by a grant awarded to Md. Rezuanul Islam (The Obayashi Foundation: Overseas Practical Training Grant).

\section{References}

Anh, L. T., H. Takagi, M. Heidarzadeh, Y. Takata, and A. Takahashi, 2019: Field Surveys and Numerical Simulation of the 2018 Typhoon Jebi: Impact of High Waves and Storm Surge in Semi-enclosed Osaka Bay, Japan, Pure Appl Geophys, 176(10), 4139-4160. https://doi.org/10.1007/s00024-019-02295-0

Bell, G. D., M. S. Halpert, C. F. Ropelewski, V. E. Kousky, A. V. Douglas, R. C. Schnell, and M. E. Gelman, 2000: Climate assessment for 1999. Bull. Amer. Meteor. Soc., 81, 1328.

Blake, E. S., T. B. Kimberlain, R. J. Berg, J. P. Cangialosi, and J. L. Beven, 2013: Tropical cyclone report Hurricane Sandy (AL182012) 22 - 29 October 2012. National Weather Service, National Hurricane Center, October 2012, 1-157.

Bromirski, P. D., R. E. Flick, and D. R. Cayan, 2003: Storminess Variability along the California Coast: 1858-2000. J. Clim., 16(6), 982-993. https://doi.org/10.1175/15200442(2003)016<0982:SVATCC>2.0.CO;2

Brown, S., R. J. Nicholls, C. D. Woodroffe, S. Hanson, J. Hinkel, A. S. Kebede, B. Neumann, and A. T. Vafeidis, 2013: Sea-level rise impacts and responses: A global perspective. Coastal hazards. Finkl, W. (ed.), Springer, 117-149. https://doi.org/10.1007/978-94007-5234-4_5

Camargo, S. J., and A. H. Sobel, 2005: Western North Pacific tropical cyclone intensity and ENSO. J. Clim., 18(15), 2996-3006. https://doi.org/10.1175/JCLI3457.1

Chan, J. C. L., 2016: Observed Variations of Western North Pacific Tropical Cyclone Activity on Decadal Time Scales and Longer. Climate Change: Multidecadal and Beyond. Chang, C.-P., M. Ghil, M. Latif, and J. M. Wallace (eds.), World Scientific Publishing, 303-313. https://doi.org/10.1142/9789814579933_0019

Chan, K. T. F., 2019: Are global tropical cyclones moving slower in a warming climate? Environ. Res. Lett., 14(10). 104015. https://doi.org/10.1088/1748-9326/ab4031

Church, J. A., J. R. Hunter, K. L. Mclnnes, and N. J. White, 2006: Sea-level rise around the Australian coastline and the changing frequency of extreme sea-level events. Aust. Meteorol. Mag., 55, 253-260.

Elsner, J., and K. Liu, 2003: Examining the ENSO-typhoon hypothesis. Clim. Res., 25(1), 
43-54. https://doi.org/10.3354/cr025043

Emanuel, K., 2005: Increasing destructiveness of tropical cyclones over the past 30 years. Nature, 436(7051), 686-688. https://doi.org/10.1038/nature03906

Esteban, M., H. Takagi, and T. Shibayama, 2015: Introduction: Lessons from the Last 10 Years of Coastal Disasters. Handbook of Coastal Disaster Mitigation for Engineers and Planners. Esteban, M., H. Takagi, and T. Shibayama (Eds.), Elsevier, xxv-xxx. https://doi.org/10.1016/B978-0-12-801060-0.09996-2

Hallegatte, S., C. Green, R. J. Nicholls, and J. Corfee-Morlot, 2013: Future flood losses in major coastal cities. Nat. Clim. Chang., 3(9), 802-806. https://doi.org/10.1038/nclimate1979

Huang X., X. Peng, J. Fei, X. Cheng, J. Ding, and D. Yu, 2021. Evaluation and error analysis of official tropical cyclone intensity forecasts during 2005-2018 for the western North Pacific. J. M. Soc. Japan 99(1), 139-163. https://doi.org/10.2151/jmsj.2021-008

Irish, J. L., D. T. Resio, and J. J. Ratcliff, 2008: The influence of storm size on hurricane surge. J. Phys. Oceanogr., 38(9), 2003-2013. https://doi.org/10.1175/2008JPO3727.1

Islam, M. R., C-Y. Lee, K. T. Mandli, and H. Takagi, 2021: A new tropical cyclone surge index incorporating the effects of coastal geometry, bathymetry and storm information. Sci. Rep., 11(1). https://doi.org/10.1038/s41598-021-95825-7

Islam, M. R., and H. Takagi, 2020a: Typhoon parameter sensitivity of storm surge in the semi-enclosed Tokyo Bay. Front. Earth. Sci., 14(3), 553-567. https://doi.org/10.1007/s11707-020-0817-1

Islam, M. R., and H. Takagi, 2020b: Statistical significance of tropical cyclone forward speed on storm surge generation: retrospective analysis of best track and tidal data in Japan. Georisk. https://doi.org/10.1080/17499518.2020.1756345

Islam, M. R., and H. Takagi, 2020c: On the Importance of Typhoon Size in Storm Surge Forecasting. Water, Flood Management and Water Security Under a Changing Climate, Haque, A., and A. Chowdhury (eds.), Springer, 153-162. https://doi.org/10.1007/978-3030-47786-8_10

Islam, M. R., H. Takagi, L. T. Anh, A. Takahashi, and K. Bowei, 2018: 2017 Typhoon Lan reconnaissance field survey in coasts of Kanto region, Japan. J. Japan Soc. Civ. Eng. Ser. B3 (Ocean Eng.), 74(2), 593-598. https://doi.org/10.2208/jscejoe.74.i_593

Japan Meteorological Agency, 2020a: Best Track Data. https://www.jma.go.jp/jma/jmaeng/jma-center/rsmc-hp-pub-eg/trackarchives.html (Accessed on December 20, 2020) Japan Meteorological Agency, 2020b: Number of approaching typhoons. https://www.data.jma.go.jp/yoho/typhoon/statistics/accession/index.html (Accessed on December 20, 2020)

Japan Meteorological Agency, 2020c: Forecast terms related to typhoons. http://www.jma.go.jp/jma/kishou/know/yougo_hp/haichi2.html (Accessed on December 20, 2020)

Japan Meteorological Agency, 2020d: Tide Stations. https://doi.org/10.7551/mitpress/10659.003.0018 (Accessed on December 20, 2020) 
Japan Meteorological Agency, 2020e: Predicted Tide Stations. http://www.data.jma.go.jp/kaiyou/db/tide/suisan/index.php (Accessed on December 20, 2020)

JMA. Japan Meteorological Agency, 2019: Outline NWP 2019. https://www.jma.go.jp/jma/jma-eng/jma-center/nwp/outline2019-nwp/index.htm (Accessed on December 20, 2020)

Japan Aerospace Exploration Agency, 2015: ALOS World 3D - 30m. https://www.eorc.jaxa.jp/ALOS/en/aw3d30/index.html (Accessed on December 20, 2020)

Japan Oceanographic Data Center, 2020a: 500m Gridded Bathymetry Data. https://www.jodc.go.jp/jodcweb/JDOSS/infoJEGG.html (Accessed on December 20, 2020)

Japan Oceanographic Data Center, 2020b: Tide Stations. https://jdoss1.jodc.go.jp/vpage/tide.html (Accessed on December 20, 2020)

Kato, F. and K. Torii, 2004: Risk assessment on storm surge floods. Asian and Pacific Coasts 2003, 1-13. https://doi.org/10.1142/9789812703040_0133

Knutson, T., S. J. Camargo, J. C. L. Chan, K. Emanuel, C. H. Ho, J. Kossin, M. Mohapatra, M. Satoh, M. Sugi, K. Walsh, and L. Wu, 2019: Tropical cyclones and climate change assessment. Bull. Am. Meteorol. Soc., 100(10), 1987-2007. https://doi.org/10.1175/BAMS-D-18-0189.1

Knutson, T., S. J. Camargo, J. C. L. Chan, K. Emanuel, C. H. Ho, J. Kossin, M. Mohapatra, M. Satoh, M. Sugi, K. Walsh, and L. Wu, 2020: Tropical cyclones and climate change assessment part II: Projected response to anthropogenic warming. Bull. Am. Meteorol. Soc., 101(3), E303-E322. https://doi.org/10.1175/BAMS-D-18-0194.1

LI, R. C. Y., and W. ZHOU, 2018: Revisiting the intraseasonal, interannual and interdecadal variability of tropical cyclones in the western North Pacific. Atmos. Ocean. Sci. Lett., 11(2), 198-208. https://doi.org/10.1080/16742834.2018.1459460

Moon, I. J., S. H. Kim, and J. C. L. Chan, 2019: Climate change and tropical cyclone trend. Nature, 570(7759), E3-E5. https://doi.org/10.1038/s41586-019-1222-3

Mori, N., N. Ariyoshi, T. Shimura, T. Miyashita, and J. Ninomiya, 2021: Future projection of maximum potential storm surge height at three major bays in Japan using the maximum potential intensity of a tropical cyclone. Clim. Chang (accepted).

Menéndez, M., and P. L. Woodworth, 2010: Changes in extreme high water levels based on a quasi-global tide-gauge data set. J. Geophys. Res., 115(C10), C10011. https://doi.org/10.1029/2009JC005997

Neumann, B., A. T. Vafeidis, J. Zimmermann, and R. J. Nicholls, 2015: Future coastal population growth and exposure to sea-level rise and coastal flooding - A global assessment. PLOS ONE, 10(3). https://doi.org/10.1371/journal.pone.0118571

Nicholls, R. J., and A. Cazenave, 2010: Sea-level rise and its impact on coastal zones. Science, 328(5885), 1517-1520. https://doi.org/10.1126/science.1185782

Omori, F 1918: Tsunami in Tokyo Bay. In: Earthquake Investigation Committee Report, 89, 
$19-48$ (in Japanese).

Sebastian, A., J. Proft, J. C. Dietrich, W. Du, P. B. Bedient, and C. N. Dawson, 2014: Characterizing hurricane storm surge behavior in Galveston Bay using the SWAN+ADCIRC model. Coast. Eng., 88, 171-181. https://doi.org/10.1016/j.coastaleng.2014.03.002

Shimozono, T., Y. Tajima, K. Kumagai, T. Arikawa, Y. Oda, Y. Shigihara, N. Mori, and T. Suzuki, 2020: Coastal impacts of super typhoon Hagibis on Greater Tokyo and Shizuoka areas, Japan. Coast. Eng. J., 62(2), 129-145. https://doi.org/10.1080/21664250.2020.1744212

Simpson, R. H, 1974: The hurricane disaster potential scale. Weatherwise, 27, 169-186

Swiss $\mathrm{Re}, 2013$ : Mind the risk $A$ global ranking of cities under threat from natural disasters. Swiss Re. http://repo.floodalliance.net/jspui/handle/44111/1600

Takagi, H., M. R. Islam, L. T. Anh, A. Takahashi, T. Sugiu, and F. Furukawa, 2020: Investigation of high wave damage caused by 2019 Typhoon Faxai in kanto region and wave hindcast in Tokyo Bay. J. Japan Soc. Civ. Eng. Ser. B3 (Ocean Eng.), 76(1), 1221. https://doi.org/10.2208/jscejoe.76.1_12

Takagi, H., Takahashi, A., 2021: Short-fetch high waves during the passage of 2019 Typhoon Faxai over Tokyo Bay. Front. Earth. Sci., 15(2). https://doi.org/10.1007/s11707-0210872-2

United Nations Population Division, 2018: The World 's Cities in 2018. United Nation.

Webster, P. J., , G. J. Holland, , J. A. Curry, , and H-R. Chang, 2005: Changes in tropical cyclone number, duration and intensity in a warming environment. Science, $309,1844-$ 1846.

Woodworth, P. L., and D. L. Blackman, 2004: Evidence for systematic changes in extreme high waters since the mid-1970s. J. Clim, 17(6), 1190-1197. https://doi.org/10.1175/1520-0442(2004)017<1190:EFSCIE>2.0.CO;2

World Meteorological Organization, 2011. Guide to Storm Surge Forecasting.

Yamaguchi, M., and S. Maeda, 2020a: Increase in the number of tropical cyclones approaching tokyo since 1980. J. Meteorol. Soc. Japan, 98(4), 775-786. https://doi.org/10.2151/jmsj.2020-039

Yamaguchi, M., and S. Maeda, 2020b: Slowdown of Typhoon Translation Speeds in Midlatitudes in September Influenced by the Pacific Decadal Oscillation and Global Warming. J. Meteorol. Soc. Japan, Ser. II, 98(6), 1321-1334. https://doi.org/10.2151/jmsj.2020-068 